\title{
Identification of Age-Specific and Common Key Regulatory Mechanisms Governing Eggshell Strength in Chicken Using Random Forests
}

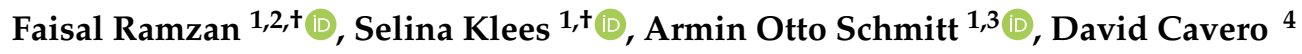 \\ and Mehmet Gültas 1,3,*(i) \\ 1 Breeding Informatics Group, Department of Animal Sciences, Georg-August University, \\ Margarethe von Wrangell-Weg 7, 37075 Göttingen, Germany; faisal.ramzan@stud.uni-goettingen.de (F.R.); \\ selina.klees@uni-goettingen.de (S.K.); armin.schmitt@uni-goettingen.de (A.O.S.) \\ 2 Department of Animal Breeding and Genetics, University of Agriculture Faisalabad, \\ 38000 Faisalabad, Pakistan \\ 3 Center for Integrated Breeding Research (CiBreed), Albrecht-Thaer-Weg 3, Georg-August University, \\ 37075 Göttingen, Germany \\ 4 H\&N International, 27472 Cuxhaven, Germany; cavero@ltz.de \\ * Correspondence: gueltas@informatik.uni-goettingen.de \\ + These authors contributed equally to this work.
}

Received: 16 March 2020; Accepted: 21 April 2020; Published: 24 April 2020

\begin{abstract}
In today's chicken egg industry, maintaining the strength of eggshells in longer laying cycles is pivotal for improving the persistency of egg laying. Eggshell development and mineralization underlie a complex regulatory interplay of various proteins and signaling cascades involving multiple organ systems. Understanding the regulatory mechanisms influencing this dynamic trait over time is imperative, yet scarce. To investigate the temporal changes in the signaling cascades, we considered eggshell strength at two different time points during the egg production cycle and studied the genotype-phenotype associations by employing the Random Forests algorithm on chicken genotypic data. For the analysis of corresponding genes, we adopted a well established systems biology approach to delineate gene regulatory pathways and master regulators underlying this important trait. Our results indicate that, while some of the master regulators (Slc22a1 and Sox11) and pathways are common at different laying stages of chicken, others (e.g., Scn11a, St8sia2, or the TGF- $\beta$ pathway) represent age-specific functions. Overall, our results provide: (i) significant insights into age-specific and common molecular mechanisms underlying the regulation of eggshell strength; and (ii) new breeding targets to improve the eggshell quality during the later stages of the chicken production cycle.
\end{abstract}

Keywords: eggshell strength; chicken; Random Forests; feature selection; master regulators; over-represented pathways

\section{Introduction}

Today's poultry industry is highly invested in the development of chicken capable of producing more eggs in longer laying cycles [1]. This production goal, however, must go hand in hand with improvement in sustainability of egg quality, especially eggshell strength (ESS), during the whole laying period [1,2]. The calcified eggshells not only provide protection against physical damage but also play a crucial role for the development of the embryo by allowing gaseous exchange, abating moisture loss, and supplying calcium for the embryo bone development [3]. Multiple molecular actors involved in the homeostasis and transportation of minerals, especially calcium, the main constituent 
of the eggshell, have been identified [4,5]. More than 500 eggshell matrix proteins have also been reported [6,7] implicating a plethora of genes that knit together the complex protein scaffold and the mineral phase of the eggshell $[5,8]$. However, most of these discoveries provide only the genes expressed in a certain segment of the chicken oviduct, the principal organ for egg development, and consequently the overall mechanisms of eggshell development remain illusive. Moreover, similar to other economically important traits, ESS remains relevant throughout the productive life and commonly deteriorates with the age of the chicken [9]. This decline in the eggshell quality remains one of the major reasons for replacing commercial flocks [1]. Hence, understanding the genetic basis of ESS at different laying stages is very important for breeders if they are to extend the laying cycle of chicken. Therefore, an analysis of this trait at different time points during the life of the bird can better delineate its genetics and its molecular mechanisms involved in this dynamic behavior [10]. This knowledge can then be utilized to design breeding strategies to improve the eggshell quality during the later stages of the chicken production cycle.

Until now, a variety of association studies have been conducted to decipher the genetic architecture of quantitative traits such as ESS, which led to the identification of a valuable repertoire of genes controlling a range of traits (see the reviews [11-13]). Finding loci associated with a trait through genome wide association studies (GWAS) is commonly based on single-SNP based models that test each SNP for its association with the phenotype, ignoring its dependency on the neighboring SNPs. This statistical design of GWAS seems quite straightforward, yet entails several challenges including those of population stratification, relationships among the samples, multiple hypothesis testing, and overestimation of SNP effects, among others, as pointed out in previous studies [14-17]. Many approaches such as different multiple testing correction methods and linear mixed models have been proposed to overcome these challenges $[15,18,19]$. However, the most devastating challenge of GWAS still persisting is the lack of power to detect the loci having medium to small effect sizes [20]. This inability of GWAS to explain a major proportion of the heritability has been under intensive discussion.

To overcome these limitations of GWAS, application of Bayesian frameworks as well as machine learning algorithms have gained importance in the last decade [21-25]. Their comparative performance has been evaluated for a variety of traits with different genetic architectures (see the reviews $[13,26,27])$. Nevertheless, multiple studies have revealed that machine learning algorithms surpass currently available well-known GWAS approaches in identifying genes having small effects on the phenotype [28-30]. In particular, Brieuc et al. pointed out the efficiency of Random Forests (RF) models for analyzing a large number of loci simultaneously and identifying promising associations [28]. Inspired by Brieuc et al.'s study, we applied the RF algorithm to assess the importance of SNPs that could provide a clue of their essential roles for ESS and to characterize the differences observed in this trait at different time points. For the analysis of the corresponding genes of these SNPs, we adopted a well established systems biology approach and identified age-specific and common key regulatory pathways and master regulators. These findings could: (i) enhance our understanding of the regulatory mechanisms underlying eggshell strength; and (ii) provide novel targets and hypotheses for future breeding strategies. To the best of our knowledge, it is the first study in this field which mainly focuses on the importance of the age-specific and common key regulatory mechanisms in chicken to reveal the genetic programs influencing the eggshell strength.

\section{Materials and Methods}

In this section, we describe the chicken dataset analyzed and the methods applied. Our analysis follows the structure of Figure 1. 


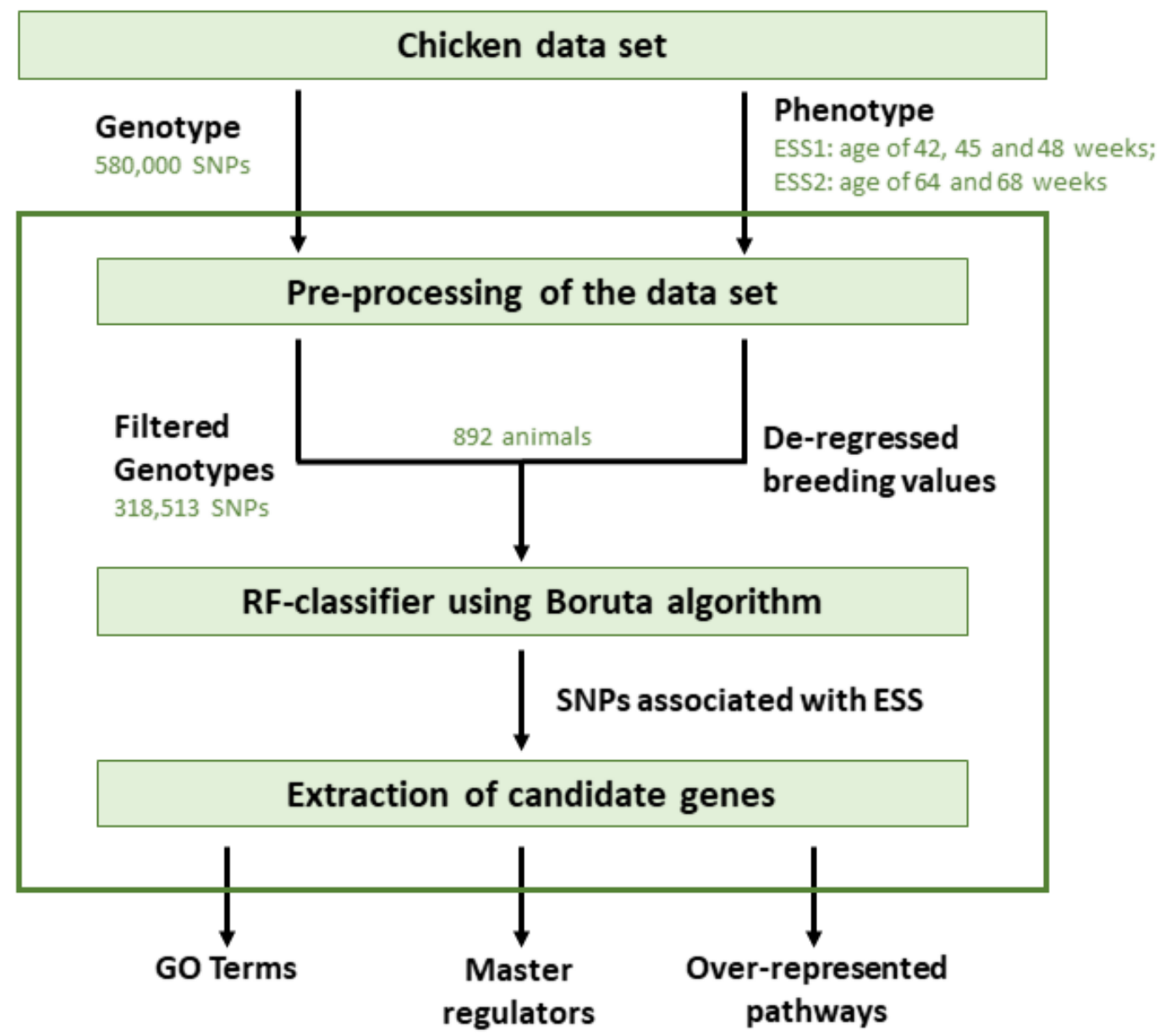

Figure 1. Flowchart of the analysis applied in this study (ESS, Eggshell strength).

\subsection{Chicken Dataset}

To explore the genomic background of the changes that incur to the eggshell strength during the life of laying birds, we analyzed a genotype dataset that has previously been used to investigate the accuracy of imputation as well as the prediction of genomic breeding values in chicken [31-33]. The dataset consists of a purebred commercial brown layer line with 892 animals and 580,000 SNPs generated using Affymetrix Axiom Chicken Genotyping Array. The genotypic data do not contain mitochondrial SNPs. The corresponding phenotypic data consist of eggshell strength (ESS) measured (as the force in Newton that was required to break the eggshell) for each bird at two distinct stages of its production cycle. These two stages were then regarded as Time Point 1 and Time Point 2, respectively. The first time point for ESS was recorded at the ages of 42, 45, and 48 weeks and the second time point was recorded at the ages of 64 and 68 weeks. Averages of the recorded breaking strengths at Time Point 1 (ESS1) and Time Point 2 (ESS2) were used as phenotypes in the further analysis. Extensive pedigree data, consisting of, in total, 40,545 individuals from six generations, were available on these birds which were included in an animal model for breeding values estimation of the birds. These breeding values were then de-regressed following Garrick et al. [34] to obtain the pseudo-phenotypes that were used in the further analysis. To ensure genotype quality, we filtered the genotyped data and removed the SNPs: (i) that were unassigned to any chromosome or present on the sex chromosomes; (ii) with a minor allele frequency $<0.01$; (iii) with a genotyping call rate $\leq 97 \%$; (iv) significantly deviating from Hardy-Weinberg equilibrium ( $p$-value $<1 \times 10^{-6}$ ); and (v) for animals having a SNP call rate smaller than $95 \%$. Finally, after filtering, we used 892 animals and 318,513 SNPs for our analyses. 


\subsection{Association Analysis Using Random Forests}

To identify SNPs potentially associated with eggshell strength, we used the concept of the Random Forests (RF) algorithm to estimate the relative importance of each SNP (attribute) regarding its involvement in the prediction of response variables (de-regressed breeding values). For this purpose, we employed the Boruta algorithm in our study [35], which is a specially developed powerful wrapper for the RF based feature selection approach. The main principle of the Boruta algorithm is based on the extension of the attributes by adding random attributes to the dataset which are called shadow attributes and created by shuffling the original values of each attribute (in our case SNPs) in the dataset. The enlargement of the attributes results in apposition of the randomness to the dataset, which leads to the reduction of the bias of hidden (false) signals arising from random fluctuations or correlations in the dataset [35-37]. To this end, a RF classifier is applied to the extended dataset, and SNPs are systematically and iteratively removed whose importance are significantly smaller than those of the shadow attributes. By repeating the process of shadow attributes generation and RF algorithm application, importance is assigned to all SNPs. As a result, the Boruta algorithm provides a ranked list of SNPs with a decision of whether the importance of a SNP is confirmed, rejected, or tentative. It is important to note that a similar idea to the Boruta algorithm is manually implemented in [22] to assess the importance of SNPs.

\subsection{Gene Set Analysis}

We extracted the genes corresponding to the SNPs identified by the Boruta algorithm from Ensembl using BioMart [38] (R-script given in File S1). Furthermore, we performed a gene set analysis regarding their molecular functions to obtain functional annotations of these genes.

\subsection{Identification of Master Regulators and Over-Represented Pathways}

Following our previous studies $[39,40]$, we performed the "upstream analysis" and pathway analysis using the geneXplain platform [41] to gain more insight into the functional relationships of genes. The algorithm of "upstream analysis" workflow was introduced by Koschmann et al. [42] and its main goal is to reveal the underlying key regulators that control the activity of target genes. For this purpose, the underlying algorithm of "upstream analysis" firstly constructs molecular pathway networks and then detects convergence points of these networks, which are called master regulators and are likely to orchestrate the transcriptional regulation of several genes. In our analysis, we used the GeneWays database [43] and ran the standard "upstream analysis" workflow with a maximum radius of 10 steps upstream to identify the top five master regulators of each gene set resulted from the previous step of the analysis.

To discover novel biological functions and to reveal the properties of the genes under study, we performed a pathway enrichment analysis as the second step of our analysis. To this end, we used the TRANSPATH pathway database [44], which is a regularly updated signaling pathway database and contains information about genes, molecules and reactions for the identification of age-specific and common over-represented pathways.

\section{Results}

In this study, we performed the RF approach using the Boruta algorithm to identify the informative SNPs associated with eggshell strength at two time points during the laying cycle of commercial brown layer chicken. For this purpose, the importance of each SNP was separately assessed for its association with the phenotype of interest. To this end, we obtained a list of SNPs for each time point whose importance was confirmed by the Boruta algorithm for the prediction of the phenotype. Analyzing both time points, we identified 3726 SNPs associated with eggshell strength at Time Point 1 (ESS1) and 1815 SNPs associated with eggshell strength at Time Point 2 (ESS2) (the lists of SNPs are given in Table S2). These SNPs were then mapped to the genome and the genes harboring at least one of these 
SNPs were identified for both traits. In total, we identified 405 genes for ESS1 and 253 genes for ESS2 (the lists of genes and their Gene Ontology (GO) categories are given in Tables S2 and S3, respectively). A closer look at these gene lists reveals that $22 \%$ (118 genes) of them are overlapping (see Figure 2), which depicts the conservation of some of the underlying mechanisms involved in the synthesis of eggshell during different stages of the egg production cycle. Our results also show that a considerably high number of genes that were distinct for the time points highlight the dynamic nature of this trait.

This section is comprised of three parts. First, to gain a deeper insight into these gene sets, we performed a gene set analysis and clustered their functions based on the GO terms. Second, we performed the "upstream analysis" introduced by Koschmann et al. [42] for the identification of specific and common master regulators of both time points. Third, we present the over-represented pathways to further elucidate the mechanisms that control the ESS at different production stages of birds.

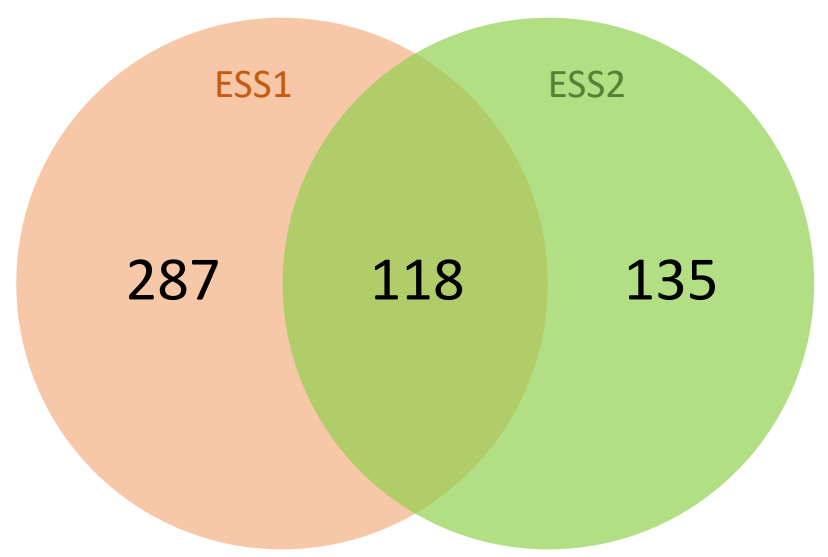

Figure 2. Venn diagram depicting the number of genes associated with eggshell strength at Time Point 1 (ESS1), at Time Point 2 (ESS2), and their overlap.

\subsection{Gene Set Analysis}

The functional classification of both gene sets indicates that there are several GO categories that were common for both time points (see the treemaps depicted in Figures 3 and 4 and the top 15 GO terms in Tables 1 and 2). In particular, the transportation of cations across membranes was the most salient function for the underlying mechanism of ESS at both time points. In this regard, calcium ions, being the main constituent of the eggshell, are supplied in large amount to the uterine fluid by transepithelial transport. In addition, other cations such as sodium, magnesium, and potassium are exchanged across the uterine endothelium to maintain the cell homeostasis [4,5]. This transmembrane transport remains important during the production cycle to ensure the development of an eggshell. The gene set analysis further reveals that the activities pertaining to ATPase, GTPase, calmodulin binding, calmodulin-dependent protein kinase, and Smad binding were specific for ESS1. Meanwhile, functions related to hormone/vitamin D receptor binding, chaperone binding, and Wnt-activated receptors were more relevant for ESS2.

Among others, the function of ATPase in eggshell formation has been well investigated in previous studies $[5,45]$. Along with maintaining a $\mathrm{pH}$ of the uterine fluid during the eggshell formation, the ATPases also provide the required energy and function as transmembrane transportation channels for ions [46]. The calmodulin binding and calmodulin-dependent protein kinase activity is known to regulate the concentration of calcium in various cells [47] and so does the vitamin D receptor binding [48]. The chaperone binding activity of the genes associated with ESS2 is another distinctive finding of this study. Chaperone proteins have been reported in the uterine fluid where they perform the folding of the eggshell matrix proteins into a rigid scaffold upon which mineralization takes place to produce the fabric of eggshell [5]. These functional classes elucidate the molecular functions that 
gain more relevance depending on the age of the birds and demonstrate the key functions that remain important throughout the laying cycle of the birds.

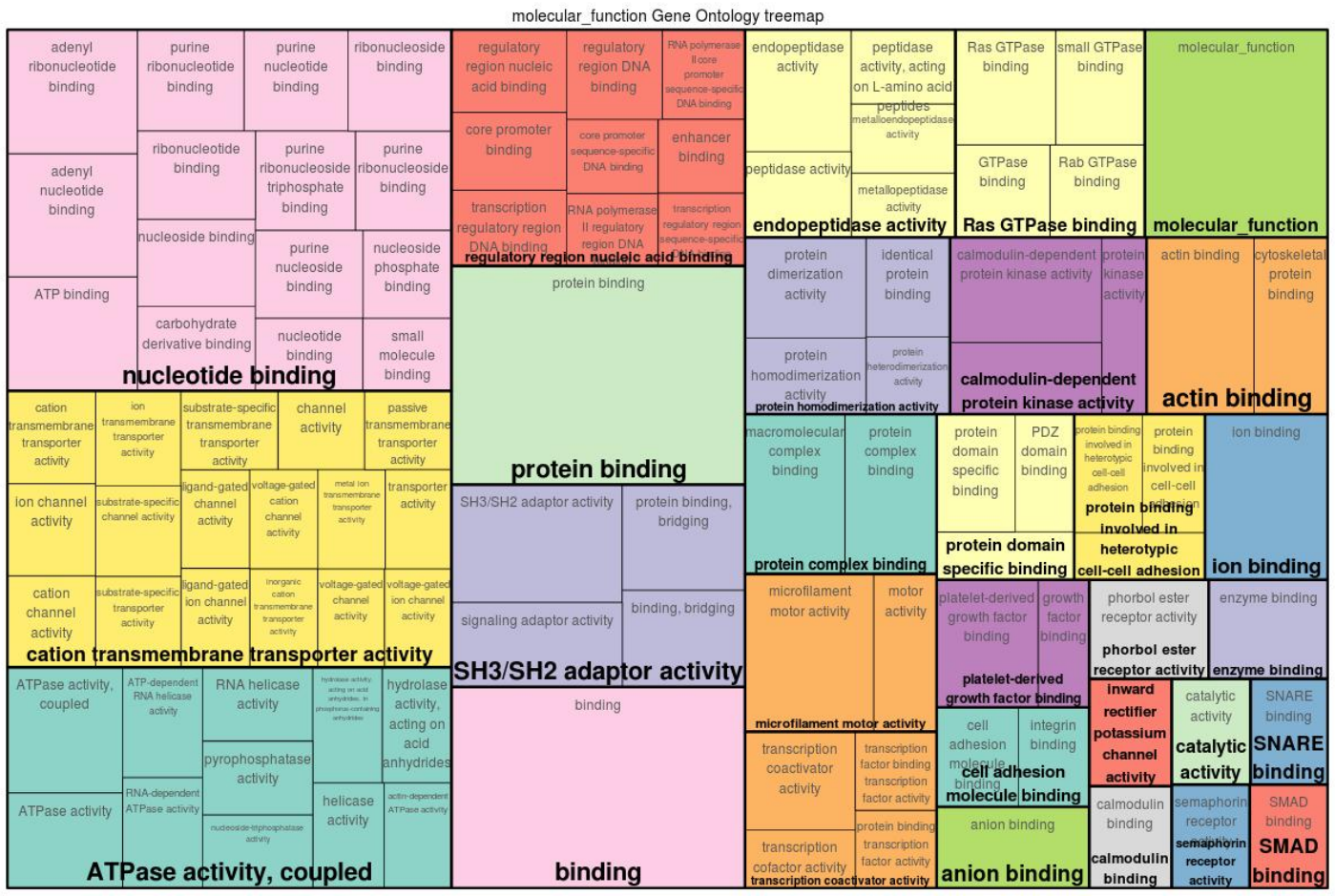

Figure 3. Gene Ontology (GO) treemap for genes associated with eggshell strength at Time Point 1 (ESS1). The boxes are grouped together based on the upper-hierarchy GO-term which is written in bold letters.

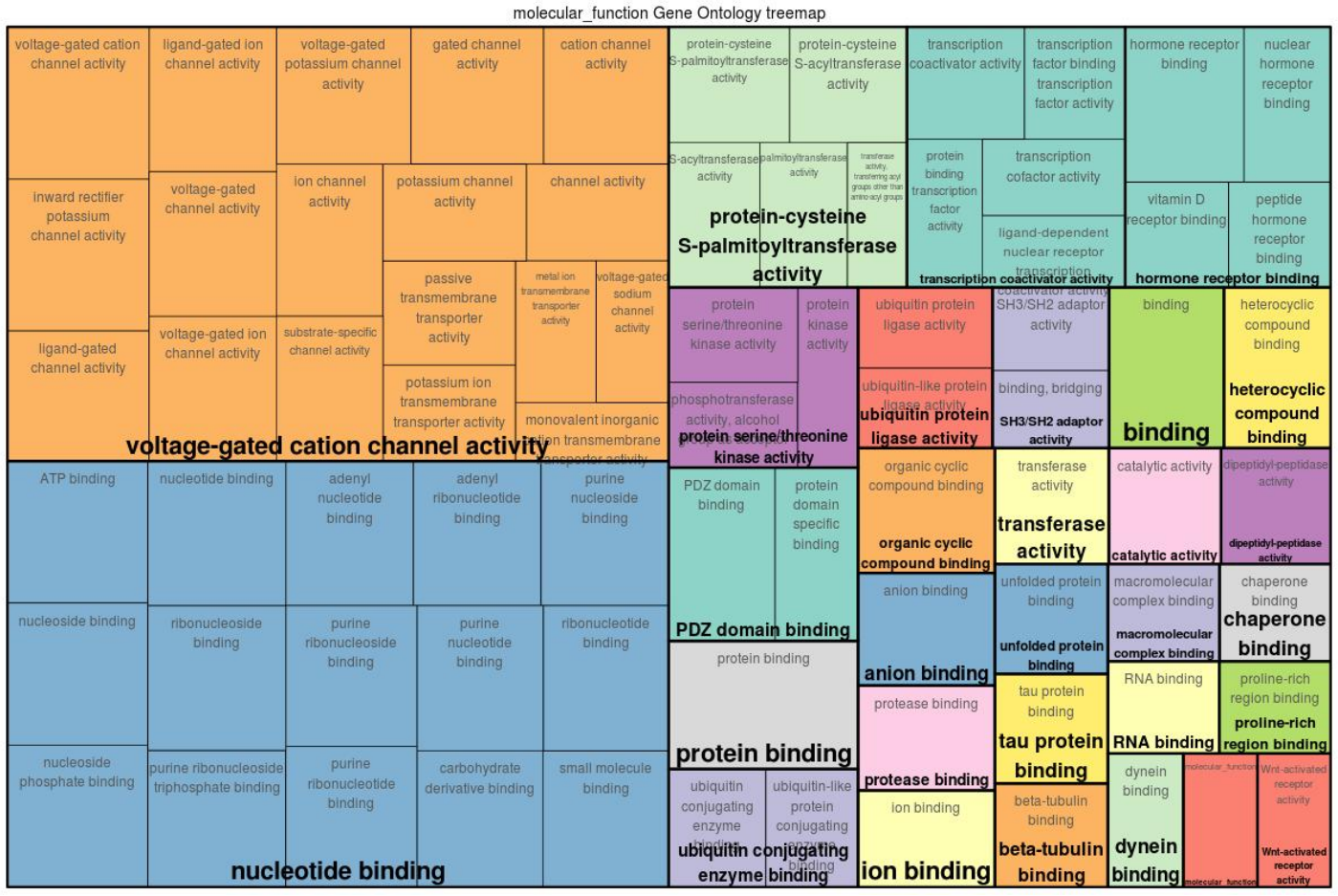

Figure 4. Gene Ontology (GO) treemap for genes associated with eggshell strength at Time Point 2 (ESS2). The boxes are grouped together based on the upper-hierarchy GO-term which is written in bold letters. 
Table 1. Top 15 Gene Ontology (GO) molecular function terms based on the adjusted $p$-value for the eggshell strength at Time Point 1 (ESS1).

\begin{tabular}{llcc}
\hline GO Term & GO Title & $\begin{array}{c}\text { Number } \\
\text { of Genes }\end{array}$ & $\begin{array}{c}\text { Adjusted } \\
p \text {-Value }\end{array}$ \\
\hline GO:0005515 & protein binding & 281 & $5.11 \times 10^{-8}$ \\
GO:0005488 & binding & 331 & $1.97 \times 10^{-7}$ \\
GO:0043167 & ion binding & 155 & $4.93 \times 10^{-3}$ \\
GO:0000146 & microfilament motor activity & 5 & $4.93 \times 10^{-3}$ \\
GO:0003779 & actin binding & 20 & $6.9 \times 10^{-3}$ \\
GO:0032559 & adenyl ribonucleotide binding & 49 & $1.47 \times 10^{-2}$ \\
GO:0030554 & adenyl nucleotide binding & 49 & $1.51 \times 10^{-2}$ \\
GO:0044877 & macromolecular complex binding & 50 & $1.54 \times 10^{-2}$ \\
GO:0004683 & calmodulin-dependent protein kinase activity & 5 & $1.54 \times 10^{-2}$ \\
GO:0005524 & ATP binding & 47 & $2.05 \times 10^{-2}$ \\
GO:0042623 & ATPase activity, coupled & 16 & $2.24 \times 10^{-2}$ \\
GO:0008092 & cytoskeletal protein binding & 30 & $3.32 \times 10^{-2}$ \\
GO:0043168 & anion binding & 74 & $3.93 \times 10^{-2}$ \\
GO:0046983 & protein dimerization activity & 40 & $4.15 \times 10^{-2}$ \\
GO:0017016 & Ras GTPase binding & 12 & $4.86 \times 10^{-2}$ \\
\hline
\end{tabular}

Table 2. Top 15 Gene Ontology (GO) molecular function terms based on the adjusted $p$-value for the eggshell strength at Time Point 2 (ESS2).

\begin{tabular}{llcc}
\hline GO Term & \multicolumn{1}{c}{ GO Title } & $\begin{array}{c}\text { Number } \\
\text { of Genes }\end{array}$ & $\begin{array}{c}\text { Adjusted } \\
\boldsymbol{p} \text {-Value }\end{array}$ \\
\hline GO:0005515 & protein binding & 168 & $1.30 \times 10^{-2}$ \\
GO:0022843 & voltage-gated cation channel activity & 9 & $2.09 \times 10^{-2}$ \\
GO:0005242 & inward rectifier potassium channel activity & 4 & $2.10 \times 10^{-2}$ \\
GO:0032549 & ribonucleoside binding & 40 & $2.79 \times 10^{-2}$ \\
GO:0000166 & nucleotide binding & 48 & $2.79 \times 10^{-2}$ \\
GO:0005524 & ATP binding & 34 & $2.79 \times 10^{-2}$ \\
GO:0001883 & purine nucleoside binding & 39 & $3.66 \times 10^{-2}$ \\
GO:0032559 & adenyl ribonucleotide binding & 34 & $3.66 \times 10^{-2}$ \\
GO:0005488 & binding & 199 & $3.66 \times 10^{-2}$ \\
GO:0030554 & adenyl nucleotide binding & 34 & $3.66 \times 10^{-2}$ \\
GO:0051427 & hormone receptor binding & 9 & $3.66 \times 10^{-2}$ \\
GO:0015276 & ligand-gated ion channel activity & 8 & $3.66 \times 10^{-2}$ \\
GO:0017076 & purine nucleotide binding & 39 & $3.7 \times 10^{-2}$ \\
GO:0022836 & gated channel activity & 12 & $3.83 \times 10^{-2}$ \\
GO:0036094 & small molecule binding & 50 & $4.64 \times 10^{-2}$ \\
\hline
\end{tabular}

\subsection{Identification of Master Regulators}

Applying the "upstream analysis" integrated in the geneXplain platform [41], we identified the top five age-specific and common master regulators. While the master regulators Arx, Sox1, and Scn11a were specifically found for ESS1, the master regulators St8sia2, Tead2, and Prox1 were identified for ESS2. Additionally, Slc22a1 and Sox11 were identified for both time points (see Figures 5 and 6).

The ESS1 specific master regulator Scn11a is a gene encoding transmembrane sodium channels which control the voltage-gated sodium transport especially in the uterus [49,50], the site of eggshell synthesis in birds. Moreover, the importance of sodium channels in the transportation of inorganic minerals deposited in the eggshell is well established [51]. Interestingly, we found the master regulator Slc22a1 at both time points. It codes for the protein OCT1, an organic cation transporter for substrates such as putrescine [52], which plays an important role for eggshell thickness [53] and calcium transport in the intestine [54]. Furthermore, many other members of the super-family of transport proteins, Slc (solute carrier proteins), are well known to play an essential role in the homeostasis of calcium ions in a variety of tissues [55]. The Slc proteins have also been reported to transport magnesium ions during the egg calcification process [5]. 


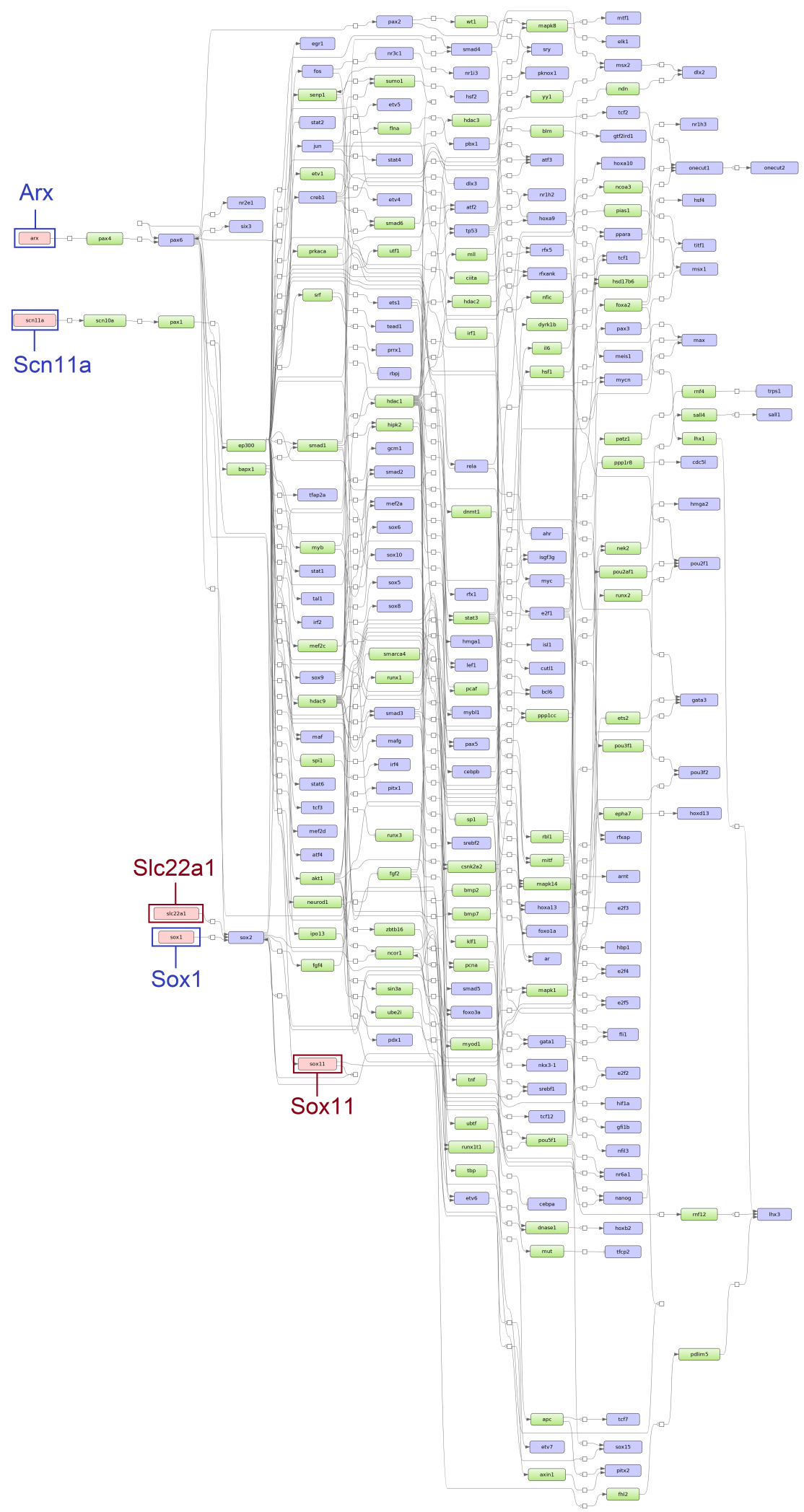

Figure 5. Scheme of gene regulatory pathways revealing the top five master regulators (pink filled boxes) for eggshell strength at Time Point 1 (ESS1) following the "upstream analysis" [42]. The master regulators written in dark blue and surrounded by dark blue boxes (Arx, Scn11a and Sox1) were identified specifically for ESS1 while master regulators written in dark red and surrounded by dark red boxes (Slc22a1 and Sox11) were identified at both time points (corresponding networks for eggshell strength at Time Point 2 (ESS2) in Figure 6). 


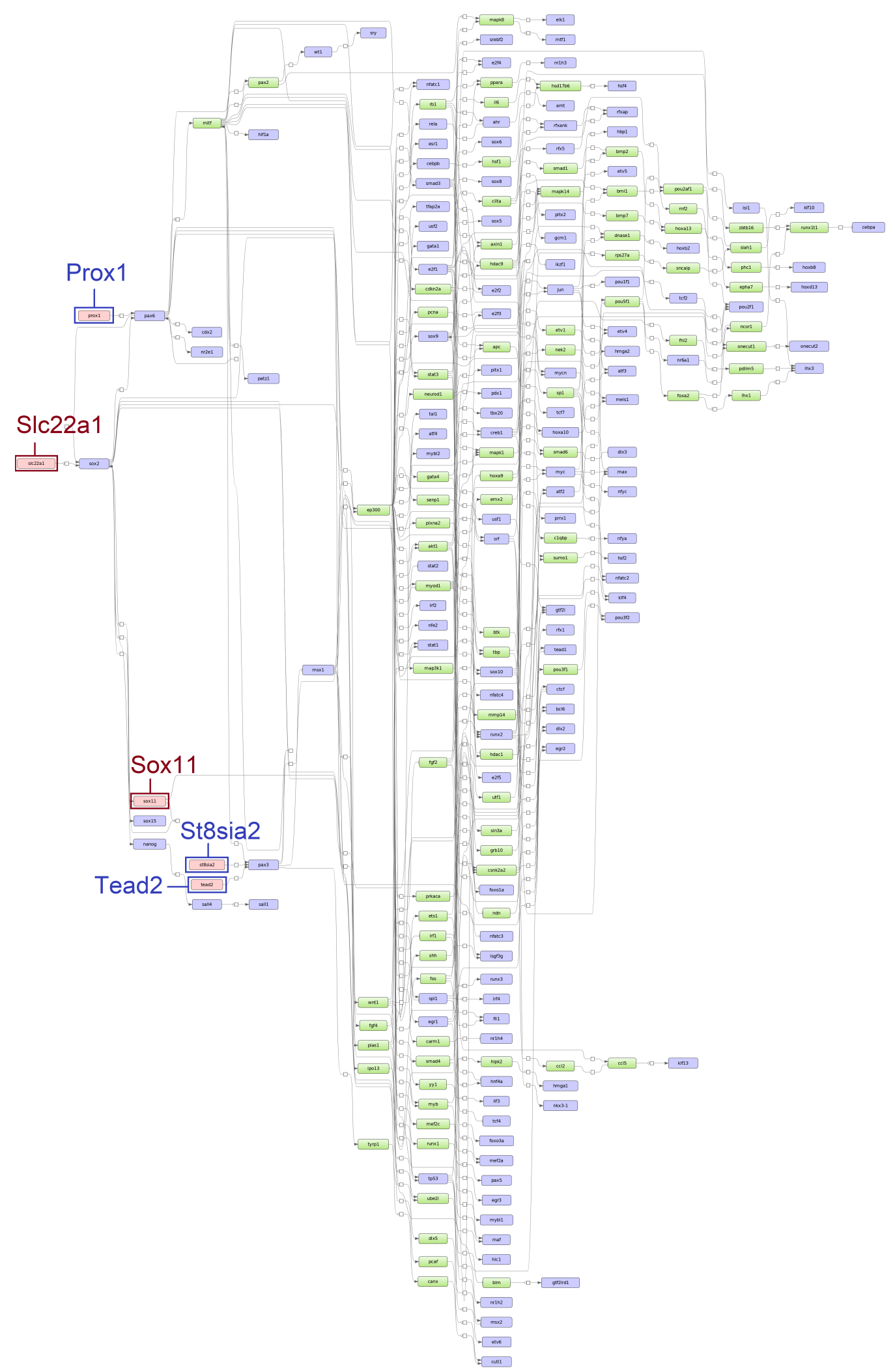

Figure 6. Scheme of gene regulatory pathways revealing the top five master regulators (pink filled boxes) for eggshell strength at Time Point 2 (ESS2) following the "upstream analysis" [42]. The master regulators written in dark blue and surrounded by dark blue boxes (Prox1, St8sia2 and Tead2) were identified specifically for ESS2 while master regulators written in dark red and surrounded by dark red boxes (Slc22a1 and Sox11) were identified at both time points (corresponding networks for eggshell strength at Time Point 1 (ESS1) in Figure 5). 
Another interesting master regulator, Sox11, which encodes a member of the Sox (SRY-related HMG-box) family of transcription factors, was found at both time points. Sox11 is known to positively regulate the process of osteogenesis (the formation of bone) [56]. This regulator gains relevance given the importance of bone as a labile reservoir of minerals, especially calcium [4]. In birds, the calcium homeostasis is achieved by regulating the metabolism of bone minerals as well as by controlling the absorption and excretion of calcium in the intestine and in kidneys, respectively [57]. Furthermore, the master regulator Tead2 found for ESS2 is a regulator of osteogenesis [58] and it is also one of the direct downstream target genes of Sox11. This might be an indication of different regulatory mechanisms involved in the osteogenesis or bone remodeling during the later stages of the laying cycle [56].

The St8sia2, identified as an ESS2 specific master regulator, encodes a membrane protein which catalyzes the metabolism of sialic acid [59], a carbohydrate found in the eggshell membranes [60-62]. The eggshell membranes constitute the inner layer of the eggshell and contribute to its strength. They further provide the nucleation sites for the initiation of the shell synthesis [63]. Sialic acid is also part of podocalyxin and secreted phosphoprotein 1 (SPP1), both of which are glycoproteins found in the uterus during eggshell calcification $[5,64]$. Because of its high negative charge, podocalyxin is presumed to interact with calcium carbonate during the calcification of the eggshell [64]. The master regulator Prox 1 encodes the protein prospero homeobox 1 that has also been reported as part of eggshell membranes $[65,66]$. However, the Prox1 gene is mostly implicated in the regulation of the development of a variety of organs including liver, pancreas and kidney [67]. Although the vast majority of the master regulators could be biologically characterized to be crucial for ESS, the importance and role of the two master regulators Sox 1 and Arx for this trait is currently biologically unconfirmed and could hence provide novel targets for future studies.

\subsection{Identification of Over-Represented Pathways}

To further elucidate and investigate the mechanisms that control the ESS at different time points, we were interested in identifying age-specific and common over-represented pathways. Applying the pathway analysis, we identified eleven and nine significantly over-represented pathways for ESS1 and ESS2, respectively, and seven of these pathways are overlapping for both time points (see Figure 7 and Table 3).

Among the pathways shared by both time points, G1 phase (Cdk4), G1 phase (Cdk6), and G2/M phase (cyclinA:Cdk1) involve different members of the cyclin-dependent kinase (CDK) family which regulate transcription, mRNA processing, and, more importantly, cell cycle [68]. In the context of ESS, these pathways may influence the differentiation efficiency of osteoblasts, osteoclasts, chondrocytes [69], and uterine epithelium cells, all of which are crucial for the supply of calcium ions as well as for bone and calcium homeostasis [70,71]. The p38 pathway is implicated in a variety of cellular responses including those related to proliferation, differentiation and apoptosis [72]. Moreover, the role of this pathway has also been reported in the egg development of Drosophila melanogaster [73]. The LXR (liver X receptors) network plays a central role in the transcriptional control of lipid metabolism [74]. This pathway also mediates the concentrations of oxysterols and ApoE (Apolipoprotein E) if activated in response to elevated intra-cellular cholesterol levels [75]. The oxysterols, oxygenated forms of cholesterol, are intermediates in bile acid and steroid hormone biosynthetic pathways [76]. Among other steroid hormones, estrogen is more intimately involved in calcium homeostasis and has also been implicated in the development of osteoporosis [77]. Moreover, other forms of oxysterols are also involved in calcium metabolisms [78] and mesenchymal stem cell differentiation [79]. In addition to the CDKs, the Smad4 proteins, predominantly present in the nucleus of the cell, mediate the cell cycle due to their association with the E2F family of transcription factors [80]. These pathways can be upstream regulated by the transforming growth factor $\beta$ (TGF- $\beta$ ) [81]. 
The transforming growth factor- $\beta$ (TGF- $\beta$ ) signaling pathway can be regarded as the most important pathway enriched for ESS1. This pathway, among its other functions, is well-known for its role in bone homeostasis [82]. Furthermore, some components of this pathway also overlap with other pathways delineated in our analysis. The Sox9 is a transcription factor that regulates the expression of the COL2A1 (collagen type II, alpha 1) gene which contributes to collagen formation [83]. During this process, Smad3, a member of effector molecules in the signaling pathways of the TGF- $\beta$ ligand superfamily is activated [84]. Another pathway that is based on Smad7, SIK1 gene induction also regulates TGF- $\beta$ signaling [85]. Owing to this crosstalk with a variety of other pathways, the TGF- $\beta$ signaling pathway allows the bone to adapt to dynamic environments [82].

The Endothelin-1 gene (ET-1) regulation pathway includes the mechanisms regulating ET-1 gene expression. Among other functions, ET-1 is involved in osteoblast proliferation and differentiation in bone tissue as well as in the ovulation process in the uterus [86]. ET-1 gene regulation is responsive to intracellular calcium and calmodulin [87]. The MIC2 signaling pathway, which was specifically enriched for ESS2, has CD99 as the main cell surface protein and has been implicated in apoptosis, adhesion, differentiation, and protein trafficking possibly by affecting actin cytoskeleton reorganization $[88,89]$. Another ESS2 specific pathway involves the inactivation of the nuclear factor $Y$ (NF-Y) transcription factor by $\mathrm{p} 73$ proteins, a process that represses the promoter of the telomerase catalytic subunit and induces replicative senescence [90,91]. The activity of NF-Y is further linked to the parathyroid hormone, which is the main regulator of calcium and phosphorus homeostasis. Taken together, the pathways show a diversity of complex functional features in chicken in response to age-dependent changes in eggshell formation. Some pathways show a direct relevance for ESS while others seem to be indirectly linked via interactions between pathways and regulators [92,93].

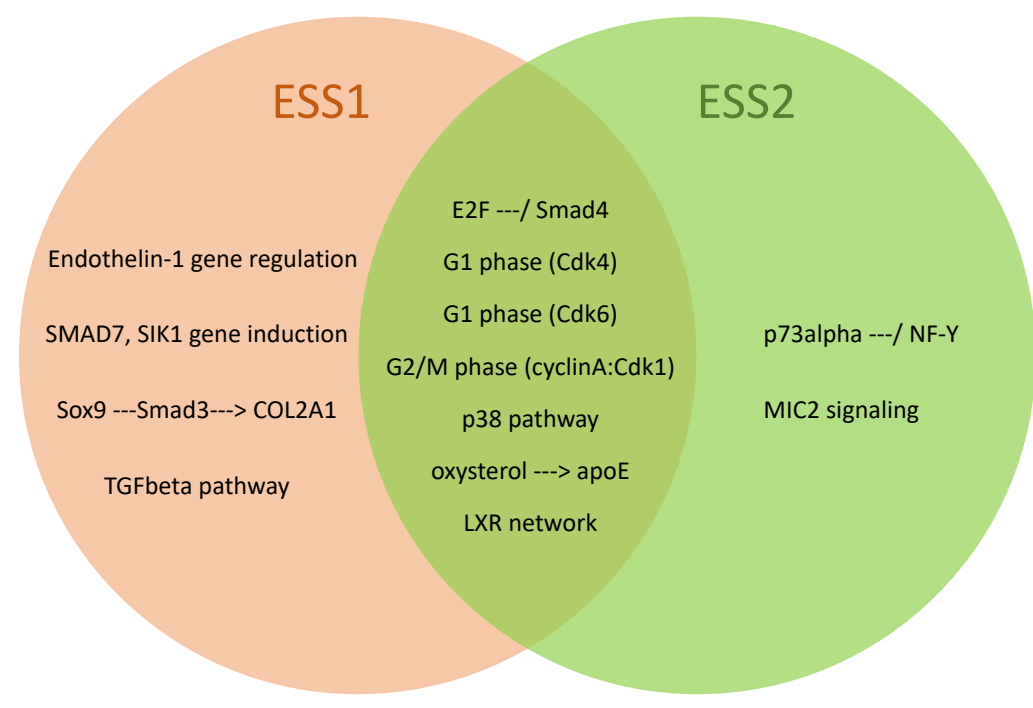

Figure 7. Venn diagram of over-represented pathways ( $p$ adjusted $<0.001$ ) of eggshell strength at Time Point 1 (ESS1), at Time Point 2 (ESS2), and their overlap. Pathways are based on the TRANSPATH pathway database [44]. 
Table 3. Significantly over-represented pathways for both time points ( $p$ adjusted $<0.001$ ) sorted by adjusted $p$-values (based on the smaller one of either ESS1 or ESS2). Pathways are based on the TRANSPATH pathway database [44]. (ESS1/ESS2, eggshell strength at Time Point 1/2).

\begin{tabular}{|c|c|c|}
\hline Pathway Name & $\begin{array}{l}\text { Adjusted } p \text {-Value } \\
\text { for ESS1 / ESS2 }\end{array}$ & $\begin{array}{l}\text { Over-Represented } \\
\text { in }\end{array}$ \\
\hline $\mathrm{E} 2 \mathrm{~F}-/ \mathrm{Smad} 4$ & $5.05 \times 10^{-5} / 7.99 \times 10^{-4}$ & ESS1, ESS2 \\
\hline Endothelin-1 gene regulation & $5.05 \times 10^{-5} / \quad-$ & ESS1 \\
\hline G2/M phase (cyclin A:Cdk1) & $1.61 \times 10^{-4} / 1.65 \times 10^{-4}$ & ESS1, ESS2 \\
\hline SMAD7, SIK1 gene induction & $1.61 \times 10^{-4} / \quad-$ & ESS1 \\
\hline oxysterol $\longrightarrow$ apoE & $1.61 \times 10^{-4} / 1.85 \times 10^{-4}$ & ESS1, ESS2 \\
\hline LXR network & $1.61 \times 10^{-4} / 1.65 \times 10^{-4}$ & ESS1, ESS2 \\
\hline p73alpha - / NF-Y & $-\quad / 1.65 \times 10^{-4}$ & ESS2 \\
\hline Sox $9-$ Smad $3->$ COL2A1 & $5.43 \times 10^{-4} / \quad-$ & ESS1 \\
\hline G1 phase (Cdk6) & $7.60 \times 10^{-4} / 7.93 \times 10^{-4}$ & ESS1, ESS2 \\
\hline G1 phase (Cdk4) & $9.77 \times 10^{-4} / 7.99 \times 10^{-4}$ & ESS1, ESS2 \\
\hline p38 pathway & $9.77 \times 10^{-4} / 7.99 \times 10^{-4}$ & ESS1, ESS2 \\
\hline MIC2 signaling & $/ 7.99 \times 10^{-4}$ & ESS2 \\
\hline TGFbeta pathway & $9.53 \times 10^{-4} /$ & ESS1 \\
\hline
\end{tabular}

\section{Discussion}

To uncover the associations between genetic variants and phenotypes, genome wide association studies (GWAS) have become the method of choice [12]. Despite their success in identifying a multitude of genes, the prediction performance of single-SNP based GWAS strategies is limited $[15,17,94]$. Alternatively, multi-marker models including different Bayesian frameworks were introduced for GWAS. In these models, all SNPs are fitted simultaneously as random effects assuming a certain prior distribution of SNP effects [13]. In practice, these SNP effects are unknown and may not even strictly follow a certain distribution [25]. Unlike these traditional statistical models, machine learning methods do not require these prior assumptions about the genetic architecture of traits and have been applied in GWAS in humans [30] as well as in livestock [27,95]. Especially, Romagnoni et al. [30] and Huang et al. [24] showed that machine learning based algorithms provide promising prediction power to assess genotype-phenotype associations. In particular, the Random Forests (RF) algorithm has been successfully applied for this purpose. These articles encouraged us to utilize RF in our study since the application of GWAS to identify genetic variants associated with ESS was futile.

Applying RF, we were able to identify a remarkably high number of genes related to ESS which is in agreement with the findings of Maan et al. [6,7], Mikšík et al. [96,97], and Brionne et al. [5], who pointed out a large number of genes/proteins involved in ESS due to the complexity of this trait. The large difference in the number of genes identified for ESS1 and ESS2 reflects the change in the genetic and environmental components of the phenotypic variance over age, as has been reported before for complex traits [98,99]. The overlap between the genes for both time points (see Figure 2) reflects that certain molecular functions remain relevant to eggshell development during the laying cycle of chicken. Particularly, the similarity of genes responsible for the transportation of ions is in line with the findings of Park et al. [100] and Fan et al. [51] who found that the concentration level of different ions in blood does not change with the age of chicken. Interestingly, a closer look at the biological processes of these traits reveals that, while highly significant GO terms are involved in development for ESS1, the significant biological processes for ESS2 are rather related to different metabolic processes (Table S3). The differences in biological processes at both time points could be associated with the temporal changes in the signaling cascades influencing dynamic behavior of eggshell strength over time.

In line with previous studies [39,42,101-103], we applied a systems biology approach and identified master regulators to investigate and unravel the transcriptional regulatory machinery of ESS associated genes. Interestingly, our results show that, similar to the genes, there are common master 
regulators (Sox11 and Slc22a1) for both time points, which are likely to govern various eggshell related processes during the laying of the birds. In particular, being a member of the Slc superfamily which is involved in the transmembrane transport, the Slc22a1 could be essential to eggshell development. For ESS1, the most promising master regulator Scn11a controls sodium transport in the uterus $[49,50]$ to maintain a voltage difference as well as osmolarity across uterine cell membranes to help in the calcium transportation [51]. In ESS2, the master regulator Tead2 together with the master regulator Sox11 underline the importance of bone remodeling during the later stages of the production cycle of the chicken.

Another fundamental step of our analysis was the identification of the over-represented pathways. The results of this analysis also reinforce the findings of gene set analysis as well as the identified master regulators. Some of the over-represented pathways were conserved at both time points while others were age-specific. Here, we specifically highlight the well-characterized TGF- $\beta$ pathway that interacts with most of the identified pathways in our analysis to regulate bone homeostasis and thus might play an important role in ESS [82]. The majority of the remaining pathways, especially those which are common to both time points, were found to be related to the cell cycle. The uterine epithelium and bone are the tissues that actively take part in the development of eggshell, hence the renewal of the cells of both tissues is crucial for the synthesis of a strong eggshell [4]. Furthermore, multiple studies suggest that a declining ability of uterine epithelium cells to transport calcium is the main reason of the age-related deterioration of eggshells [51,100]. In particular, the ESS2 specific p73alpha - / NF-Y pathway that results in the inactivation of the NF-Y transcription factor by p73 proteins and consequently causes replicative senescence of cells [90] may also point towards the underlying reason for weaker eggshells during the later stages of the production cycle.

Recently, the use of systems biology based approaches to study the traits of economic importance is gaining importance in the field of agriculture [39,102-104]. However, one of the major impediments in the use of this knowledge in practical animal breeding is to integrate this large amount of information into traditional genetic evaluation programs [105]. A small group of master regulators such as those identified in our analysis integrated into prediction models can possibly be a remedy and might provide novel breeding targets to improve the economically important trait of ESS. Additionally, the knowledge about the specific pathways such as TGF- $\beta$ could provide novel hypotheses for further studies.

\section{Conclusions}

In this study, we performed a systematic analysis to investigate the age-specific and common regulatory mechanisms that underlie the dynamic trait eggshell strength in chicken. For this purpose, we applied a RF feature selection algorithm to detect the age-dependent genotype-phenotype associations and then used a well established systems biology approach to highlight the master regulators and regulatory pathways that govern the underlying genetic mechanisms of eggshell development. Our results show that most of the genes identified for the ESS at both time points are in agreement with previous studies. Our findings further indicate that some biological processes related to eggshell development remain conserved across production stages while others are age-specific and thus changing over time. To the best of our knowledge, this is the first study revealing master regulators and over-represented pathways in the context of ESS and our findings should be further utilized to design novel hypothesis for future studies.

Supplementary Materials: The following are available online at http:/ / www.mdpi.com/2073-4425/11/4/464/s1, Script S1: R-script for analysis of SNPs and for the extraction of corresponding genes, Table S1: The list of important SNPs, Table S2: The list of genes, Table S3: Gene Ontology categories

Author Contributions: M.G. designed and supervised the research. F.R. and S.K. participated in the design of the study, and conducted computational and statistical analyses together with M.G. F.R. prepared and studied the GWAS data. S.K. performed and adjusted the bioinformatics analysis. A.O.S. was involved in the interpretation of the results together with F.R., S.K., D.C., and M.G. F.R., S.K., and M.G. wrote the final version of the manuscript. M.G. conceived and managed the project. All authors have read and agreed to the published version of the manuscript. 
Acknowledgments: The chicken data used in this study were provided by the "Synbreed-Synergistic Plant and Animal Breeding" project for which we are grateful to the project team. This work is part of FR's doctoral program, which is funded by the overseas scholarship program of the University of Agriculture Faisalabad, Pakistan. We acknowledge support by the German Research Foundation and the Open Access Publication Funds of the Göttingen University. We would like to thank Abirami Rajavel and Martin Wutke for proofreading the manuscript and Malena Erbe for providing important insights into the chicken dataset.

Conflicts of Interest: The authors declare no conflict of interest.

\section{References}

1. Bain, M.; Nys, Y.; Dunn, I. Increasing persistency in lay and stabilising egg quality in longer laying cycles. What are the challenges? Br. Poult. Sci. 2016, 57, 330-338. [CrossRef]

2. Pottgüter, R. Feeding laying hens to 100 weeks of age. Lohmann Inf. 2016, 50, 18-21.

3. Chien, Y.C.; Hincke, M.; McKee, M. Ultrastructure of avian eggshell during resorption following egg fertilization. J. Struct. Biol. 2009, 168, 527-538. [CrossRef] [PubMed]

4. $\quad$ Nys, Y.; Bain, M.; Van Immerseel, F. Improving the Safety and Quality of Eggs and Egg Products: Volume 1: Egg Chemistry, Production and Consumption; Elsevier: Cambridge, UK, 2011.

5. Brionne, A.; Nys, Y.; Hennequet-Antier, C.; Gautron, J. Hen uterine gene expression profiling during eggshell formation reveals putative proteins involved in the supply of minerals or in the shell mineralization process. BMC Genom. 2014, 15, 1-17. [CrossRef] [PubMed]

6. Mann, K.; Maček, B.; Olsen, J.V. Proteomic analysis of the acid-soluble organic matrix of the chicken calcified eggshell layer. Proteomics 2006, 6, 3801-3810. [CrossRef]

7. Mann, K.; Olsen, J.V.; Maček, B.; Gnad, F.; Mann, M. Phosphoproteins of the chicken eggshell calcified layer. Proteomics 2007, 7, 106-115. [CrossRef]

8. Yin, Z.; Lian, L.; Zhu, F.; Zhang, Z.H.; Hincke, M.; Yang, N.; Hou, Z.C. The transcriptome landscapes of ovary and three oviduct segments during chicken (Gallus gallus) egg formation. Genomics 2020, 112, $243-251$. [CrossRef]

9. Crosara, F.S.G.; Pereira, V.J.; Lellis, C.G.; Barra, K.C.; Santos, S.K.A.D.; Souza, L.C.G.M.D.; Morais, T.A.D.; Litz, F.; Limão, V.A.; Braga, P.F.S.; et al. Is the Eggshell Quality Influenced by the Egg Weight or the Breeder Age? Braz. J. Poult. Sci. 2019, 21. [CrossRef]confirmed

10. Sun, L.; Wu, R. Mapping complex traits as a dynamic system. Phys. Life Rev. 2015, 13, 155-185. [CrossRef]

11. Zhang, H.; Wang, Z.; Wang, S.; Li, H. Progress of genome wide association study in domestic animals. J. Anim. Sci. Biotechnol. 2012, 3, 26. [CrossRef]

12. Visscher, P.M.; Wray, N.R.; Zhang, Q.; Sklar, P.; McCarthy, M.I.; Brown, M.A.; Yang, J. 10 years of GWAS discovery: Biology, function, and translation. Am. J. Hum. Genet. 2017, 101, 5-22. [CrossRef]

13. Schmid, M.; Bennewitz, J. Invited review: Genome-wide association analysis for quantitative traits in livestock-a selective review of statistical models and experimental designs. Arch. Fuer Tierz. 2017, 60, 335. [CrossRef]

14. Johnson, R.C.; Nelson, G.W.; Troyer, J.L.; Lautenberger, J.A.; Kessing, B.D.; Winkler, C.A.; O’Brien, S.J. Accounting for multiple comparisons in a genome-wide association study (GWAS). BMC Genom. 2010, 11, 724. [CrossRef]

15. Bush, W.S.; Moore, J.H. Genome-wide association studies. PLoS Comput. Biol. 2012, 8, e1002822. [CrossRef] [PubMed]Confirmed

16. Korte, A.; Farlow, A. The advantages and limitations of trait analysis with GWAS: A review. Plant Methods 2013, 9, 29. [CrossRef] [PubMed]

17. Holland, D.; Fan, C.C.; Frei, O.; Shadrin, A.A.; Smeland, O.B.; Sundar, V.; Andreassen, O.A.; Dale, A.M. Estimating inflation in GWAS summary statistics due to variance distortion from cryptic relatedness. BioRxiv 2017, 164939, doi:10.1101/164939.

18. Kang, H.M.; Sul, J.H.; Service, S.K.; Zaitlen, N.A.; Kong, S.Y.; Freimer, N.B.; Sabatti, C.; Eskin, E.; et al. Variance component model to account for sample structure in genome-wide association studies. Nat. Genet. 2010, 42, 348. [CrossRef] [PubMed]

19. Zhou, X.; Stephens, M. Genome-wide efficient mixed-model analysis for association studies. Nat. Genet. 2012, 44, 821-824. [CrossRef] [PubMed]

20. Young, A.I. Solving the missing heritability problem. PLoS Genet. 2019, 15, e1008222. [CrossRef] 
21. Zhao, Y.; Chen, F.; Zhai, R.; Lin, X.; Wang, Z.; Su, L.; Christiani, D.C. Correction for population stratification in random forest analysis. Int. J. Epidemiol. 2012, 41, 1798-1806. [CrossRef]

22. Nguyen, T.T.; Huang, J.Z.; Wu, Q.; Nguyen, T.T.; Li, M.J. Genome-wide association data classification and SNPs selection using two-stage quality-based Random Forests. BMC Genom. 2015, 16, S5. [CrossRef]

23. Armero, C.; Cabras, S.; Castellanos, M.E.; Quirós, A. Two-Stage Bayesian Approach for GWAS With Known Genealogy. J. Comput. Graph. Stat. 2019, 28, 197-204. [CrossRef]

24. Huang, X.; Zhou, W.; Bellis, E.S.; Stubblefield, J.; Causey, J.; Qualls, J.; Walker, K. Minor QTLs mining through the combination of GWAS and machine learning feature selection. BioRxiv 2019, 712190, doi:10.1101/712190. [CrossRef]

25. Liu, Y.; Wang, D.; He, F.; Wang, J.; Joshi, T.; Xu, D. Phenotype prediction and genome-wide association study using deep convolutional neural network of soybean. Front. Genet. 2019, 10, 1091. [CrossRef] [PubMed]

26. Chen, C.C.; Schwender, H.; Keith, J.; Nunkesser, R.; Mengersen, K.; Macrossan, P. Methods for identifying SNP interactions: A review on variations of Logic Regression, Random Forest and Bayesian logistic regression. IEEE/ACM Trans. Comput. Biol. Bioinform. 2011, 8, 1580-1591. [CrossRef] [PubMed]

27. van der Heide, E.; Veerkamp, R.; van Pelt, M.; Kamphuis, C.; Athanasiadis, I.; Ducro, B. Comparing regression, naive Bayes, and random forest methods in the prediction of individual survival to second lactation in Holstein cattle. J. Dairy Sci. 2019, 102, 9409-9421. [CrossRef] [PubMed]

28. Brieuc, M.S.; Waters, C.D.; Drinan, D.P.; Naish, K.A. A practical introduction to Random Forest for genetic association studies in ecology and evolution. Mol. Ecol. Resour. 2018, 18, 755-766. [CrossRef]

29. Nguyen, T.; Le, L. Detection of SNP-SNP Interactions in Genome-wide Association Data Using Random Forests and Association Rules. In Proceedings of the 2018 12th International Conference on Software, Knowledge, Information Management \& Applications (SKIMA), Phnom Penh, Cambodia, 3-5 December 2018; IEEE: Piscataway, NJ, USA, 2018; pp. 1-7.Confirmed

30. Romagnoni, A.; Jégou, S.; Van Steen, K.; Wainrib, G.; Hugot, J.P. Comparative performances of machine learning methods for classifying Crohn Disease patients using genome-wide genotyping data. Sci. Rep. 2019, 9, 1-18. [CrossRef]

31. Erbe, M.; Cavero, D.; Weigend, A.; Weigend, S.; Pausch, H.; Preisinger, R.; Simianer, H. Genomic prediction in laying hens. In Proceedings of the 8th European Symposium on Poultry Genetics, Venice, Italy, 25-27 September 2013.

32. Ni, G.; Strom, T.M.; Pausch, H.; Reimer, C.; Preisinger, R.; Simianer, H.; Erbe, M. Comparison among three variant callers and assessment of the accuracy of imputation from SNP array data to whole-genome sequence level in chicken. BMC Genom. 2015, 16, 824. [CrossRef]

33. Ni, G.; Cavero, D.; Fangmann, A.; Erbe, M.; Simianer, H. Whole-genome sequence-based genomic prediction in laying chickens with different genomic relationship matrices to account for genetic architecture. Genet. Sel. Evol. 2017, 49, 8. [CrossRef]

34. Garrick, D.J.; Taylor, J.F.; Fernando, R.L. Deregressing estimated breeding values and weighting information for genomic regression analyses. Genet. Sel. Evol. 2009, 41, 55. [CrossRef]

35. Kursa, M.B.; Rudnicki, W.R. Feature selection with the Boruta package. J. Stat. Softw. 2010, 36, 1-13. [CrossRef]

36. Kursa, M.B.; Jankowski, A.; Rudnicki, W.R. Boruta-a system for feature selection. Fundam. Informaticae 2010, 101, 271-285. [CrossRef]

37. Kursa, M.B.; Rudnicki, W.R. The all relevant feature selection using random forest. arXiv 2011, arXiv:1106.5112.

38. Kinsella, R.J.; Kähäri, A.; Haider, S.; Zamora, J.; Proctor, G.; Spudich, G.; Almeida-King, J.; Staines, D.; Derwent, P.; Kerhornou, A.; et al. Ensembl BioMarts: A hub for data retrieval across taxonomic space. Database 2011, 2011, doi:10.1093/database/bar030. [CrossRef]

39. Ayalew, Y.; Gültas, M.; Effa, K.; Hanotte, O.H.; Schmitt, A. Identification of candidate signature genes and key regulators associated with Trypanotolerance in the Sheko Breed. Front. Genet. 2019, 10, 1095.

40. Wlochowitz, D.; Haubrock, M.; Arackal, J.; Bleckmann, A.; Wolff, A.; Beißbarth, T.; Wingender, E.; Gültas, M. Computational identification of key regulators in two different colorectal cancer cell lines. Front. Genet. 2016, 7, 42. [CrossRef]

41. Wingender, E.; Kel, A. geneXplain-eine integrierte Bioinformatik-Plattform. BIOspektrum 2012, 18, 554-556. [CrossRef] 
42. Koschmann, J.; Bhar, A.; Stegmaier, P.; Kel, A.; Wingender, E. "Upstream analysis": An integrated promoter-pathway analysis approach to causal interpretation of microarray data. Microarrays 2015, 4, 270-286. [CrossRef]

43. Rzhetsky, A.; Iossifov, I.; Koike, T.; Krauthammer, M.; Kra, P.; Morris, M.; Yu, H.; Duboué, P.A.; Weng, W.; Wilbur, W.J.; et al. GeneWays: A system for extracting, analyzing, visualizing, and integrating molecular pathway data. J. Biomed. Inform. 2004, 37, 43-53. [CrossRef]

44. Krull, M.; Pistor, S.; Voss, N.; Kel, A.; Reuter, I.; Kronenberg, D.; Michael, H.; Schwarzer, K.; Potapov, A.; Choi, C.; et al. TRANSPATH ${ }^{\circledR}$ : An information resource for storing and visualizing signaling pathways and their pathological aberrations. Nucleic Acids Res. 2006, 34, D546-D551. [CrossRef]

45. Jonchère, V.; Brionne, A.; Gautron, J.; Nys, Y. Identification of uterine ion transporters for mineralisation precursors of the avian eggshell. BMC Physiol. 2012, 12, 10-51. [CrossRef]

46. Chakraborti, S.; Dhalla, N.S. Regulation of Membrane Na+-K+ ATPase; Springer: Heidelberg, Germany, 2016.

47. Colbran, R.J. Targeting of calcium/calmodulin-dependent protein kinase II. Biochem. J. 2004, 378, 1-16. [CrossRef] [PubMed]

48. Meyer, M.B.; Watanuki, M.; Kim, S.; Shevde, N.K.; Pike, J.W. The human transient receptor potential vanilloid type 6 distal promoter contains multiple vitamin D receptor binding sites that mediate activation by 1,25-dihydroxyvitamin D3 in intestinal cells. Mol. Endocrinol. 2006, 20, 1447-1461. [CrossRef] [PubMed]

49. Ogata, K.; Jeong, S.Y.; Murakami, H.; Hashida, H.; Suzuki, T.; Masuda, N.; Hirai, M.; Isahara, K.; Uchiyama, Y.; Goto, J.; et al. Cloning and expression study of the mouse tetrodotoxin-resistant voltage-gated sodium channel $\alpha$ subunit NaT/Scn11a. Biochem. Biophys. Res. Commun. 2000, 267, 271-277. [CrossRef] [PubMed]

50. Seda, M.; Pinto, F.M.; Wray, S.; Cintado, C.G.; Noheda, P.; Buschmann, H.; Candenas, L. Functional and molecular characterization of voltage-gated sodium channels in uteri from nonpregnant rats. Biol. Reprod. 2007, 77, 855-863. [CrossRef] [PubMed]

51. Fan, Y.F.; Hou, Z.C.; Yi, G.Q.; Xu, G.Y.; Yang, N. The sodium channel gene family is specifically expressed in hen uterus and associated with eggshell quality traits. BMC Genet. 2013, 14, 90. [CrossRef]

52. Koepsell, H. The SLC22 family with transporters of organic cations, anions and zwitterions. Mol. Asp. Med. 2013, 34, 413-435. [CrossRef]

53. Chowdhury, S.; Smith, T. Dietary interaction of 1, 4-diaminobutane (putrescine) and calcium on eggshell quality and performance in laying hens. Poult. Sci. 2002, 81, 84-91. [CrossRef]

54. Shinki, T.; Tanaka, H.; Takito, J.; Yamaguchi, A.; Nakamura, Y.; Yoshiki, S.; Suda, T. Putrescine is involved in the vitamin D action in chick intestine. Gastroenterology 1991, 100, 113-122. [CrossRef]

55. Altimimi, H.F.; Schnetkamp, P.P. Na+/Ca2+-K+ exchangers (NCKX): Functional properties and physiological roles. Channels 2007, 1, 62-69. [CrossRef] [PubMed]

56. Gadi, J.; Jung, S.H.; Lee, M.J.; Jami, A.; Ruthala, K.; Kim, K.M.; Cho, N.H.; Jung, H.S.; Kim, C.H.; Lim, S.K. The transcription factor protein Sox11 enhances early osteoblast differentiation by facilitating proliferation and the survival of mesenchymal and osteoblast progenitors. J. Biol. Chem. 2013, 288, 25400-25413. [CrossRef] [PubMed]

57. ELAROUSSI, M.A.; FORTE, L.R.; EBER, S.L.; BIELLIER, H.V. Calcium Homeostasis in the Laying Hen.: 1. Age and Dietary Calcium Effects. Poult. Sci. 1994, 73, 1581-1589. [CrossRef] [PubMed]

58. Håkelien, A.M.; Bryne, J.C.; Harstad, K.G.; Lorenz, S.; Paulsen, J.; Sun, J.; Mikkelsen, T.S.; Myklebost, O.; Meza-Zepeda, L.A. The regulatory landscape of osteogenic differentiation. Stem Cells 2014, 32, 2780-2793. [CrossRef] [PubMed]

59. Scheidegger, E.P.; Sternberg, L.R.; Roth, J.; Lowe, J.B. A human STX cDNA confers polysialic acid expression in mammalian cells. J. Biol. Chem. 1995, 270, 22685-22688. [CrossRef] [PubMed]

60. Itoh, T.; Munakata, K.; Adachi, S.; Hatta, H.; Nakamura, T.; Kato, T.; Kim, M. Chalaza and egg yolk membrane as excellent sources of sialic acid ( $\mathrm{N}$-acetylneuraminic acid) for an industrial-scale preparation. Jpn. J. Zootech. Sci. 1990, 61, 277-282.

61. Nakano, K.; Nakano, T.; Ahn, D.; Sim, J. Sialic acid contents in chicken eggs and tissues. Can. J. Anim. Sci. 1994, 74, 601-606. [CrossRef]

62. Nakano, T.; Ikawa, N.; Ozimek, L. Chemical composition of chicken eggshell and shell membranes. Poult. Sci. 2003, 82, 510-514. [CrossRef] 
63. Du, J.; Hincke, M.T.; Rose-Martel, M.; Hennequet-Antier, C.; Brionne, A.; Cogburn, L.A.; Nys, Y.; Gautron, J. Identifying specific proteins involved in eggshell membrane formation using gene expression analysis and bioinformatics. BMC Genom. 2015, 16, 792. [CrossRef]

64. Jonchère, V.; Réhault-Godbert, S.; Hennequet-Antier, C.; Cabau, C.; Sibut, V.; Cogburn, L.A.; Nys, Y.; Gautron, J. Gene expression profiling to identify eggshell proteins involved in physical defense of the chicken egg. BMC Genom. 2010, 11, 57. [CrossRef]

65. Ahmed, T.A.; Suso, H.P.; Hincke, M.T. Experimental datasets on processed eggshell membrane powder for wound healing. Data Brief 2019, 26, 104457. [CrossRef] [PubMed]

66. Ahmed, T.A.; Suso, H.P.; Hincke, M.T. In-depth comparative analysis of the chicken eggshell membrane proteome. J. Proteom. 2017, 155, 49-62. [CrossRef] [PubMed]

67. Kim, Y.m.; Kim, W.Y.; Nam, S.A.; Choi, A.R.; Kim, H.; Kim, Y.K.; Kim, H.S.; Kim, J. Role of PROX1 in the transforming ascending thin limb of Henle's loop during mouse kidney development. PLoS ONE 2015, 10, doi:10.1371/journal.pone.0127429.

68. Malumbres, M. Cyclin-dependent kinases. Genome Biol. 2014, 15, 122. [CrossRef] [PubMed]

69. Ogasawara, T.; Mori, Y.; Abe, M.; Suenaga, H.; Kawase-Koga, Y.; Saijo, H.; Takato, T. Role of cyclin-dependent kinase (Cdk) 6 in osteoblast, osteoclast, and chondrocyte differentiation and its potential as a target of bone regenerative medicine. Oral Sci. Int. 2011, 8, 2-6. [CrossRef]

70. Whitehead, C. Overview of bone biology in the egg-laying hen. Poult. Sci. 2004, 83, 193-199. [CrossRef]

71. Bar, A. Calcium transport in strongly calcifying laying birds: Mechanisms and regulation. Comp. Biochem. Physiol. Part A Mol. Integr. Physiol. 2009, 152, 447-469. [CrossRef]

72. Ono, K.; Han, J. The p38 signal transduction pathway activation and function. Cell. Signal. 2000, 12, 1-13. [CrossRef]

73. Suzanne, M.; Irie, K.; Glise, B.; Agnès, F.; Mori, E.; Matsumoto, K.; Noselli, S. The Drosophila p38 MAPK pathway is required during oogenesis for egg asymmetric development. Genes Dev. 1999, 13, 1464-1474. [CrossRef]

74. Zelcer, N.; Tontonoz, P. Liver $\mathrm{X}$ receptors as integrators of metabolic and inflammatory signaling. J. Clin. Investig. 2006, 116, 607-614. [CrossRef]

75. Vaya, J.; Schipper, H.M. Oxysterols, cholesterol homeostasis, and Alzheimer disease. J. Neurochem. 2007, 102, 1727-1737. [CrossRef] [PubMed]

76. Griffiths, W.J.; Abdel-Khalik, J.; Crick, P.J.; Yutuc, E.; Wang, Y. New methods for analysis of oxysterols and related compounds by LC-MS. J. Steroid Biochem. Mol. Biol. 2016, 162, 4-26. [CrossRef] [PubMed]

77. Beck, M.; Hansen, K. Role of estrogen in avian osteoporosis. Poult. Sci. 2004, 83, 200-206. [CrossRef]

78. Mackrill, J.J. Oxysterols and calcium signal transduction. Chem. Phys. Lipids 2011, 164, 488-495. [CrossRef] [PubMed]

79. Kha, H.T.; Basseri, B.; Shouhed, D.; Richardson, J.; Tetradis, S.; Hahn, T.J.; Parhami, F. Oxysterols regulate differentiation of mesenchymal stem cells: pro-bone and anti-fat. J. Bone Miner. Res. 2004, 19, 830-840. [CrossRef]

80. Frederick, J.P.; Liberati, N.T.; Waddell, D.S.; Shi, Y.; Wang, X.F. Transforming growth factor $\beta$-mediated transcriptional repression of c-myc is dependent on direct binding of Smad3 to a novel repressive Smad binding element. Mol. Cell. Biol. 2004, 24, 2546-2559. [CrossRef]

81. Chen, C.R.; Kang, Y.; Siegel, P.M.; Massagué, J. E2F4/5 and p107 as Smad cofactors linking the TGF $\beta$ receptor to c-myc repression. Cell 2002, 110, 19-32. [CrossRef]

82. Tang, S.Y.; Alliston, T. Regulation of postnatal bone homeostasis by TGF $\beta$. BoneKEy Rep. 2013, 2, doi:10.1038/bonekey.2012.255. [CrossRef]

83. Bell, D.M.; Leung, K.K.; Wheatley, S.C.; Ng, L.J.; Zhou, S.; Ling, K.W.; Sham, M.H.; Koopman, P.; Tam, P.P.; Cheah, K.S. SOX9 directly regulates the type-ll collagen gene. Nat. Genet. 1997, 16, 174-178. [CrossRef]

84. Massagué, J.; Chen, Y.G. Controlling TGF- $\beta$ signaling. Genes Dev. 2000, 14, 627-644.

85. Lönn, P.; Vanlandewijck, M.; Raja, E.; Kowanetz, M.; Watanabe, Y.; Kowanetz, K.; Vasilaki, E.; Heldin, C.H.; Moustakas, A. Transcriptional induction of salt-inducible kinase 1 by transforming growth factor $\beta$ leads to negative regulation of type I receptor signaling in cooperation with the Smurf2 ubiquitin ligase. J. Biol. Chem. 2012, 287, 12867-12878. [CrossRef] [PubMed]

86. Stow, L.R.; Jacobs, M.E.; Wingo, C.S.; Cain, B.D. Endothelin-1 gene regulation. FASEB J. 2011, $25,16-28$. [CrossRef] [PubMed] 
87. Strait, K.A.; Stricklett, P.K.; Kohan, J.L.; Miller, M.B.; Kohan, D.E. Calcium regulation of endothelin-1 synthesis in rat inner medullary collecting duct. Am. J. Physiol.-Ren. Physiol. 2007, 293, F601-F606. [CrossRef] [PubMed]

88. Yoon, S.S.; Jung, K.I.; Choi, Y.L.; Choi, E.Y.; Lee, I.S.; Park, S.H.; Kim, T.J. Engagement of CD99 triggers the exocytic transport of ganglioside GM1 and the reorganization of actin cytoskeleton. FEBS Lett. 2003, 540, 217-222. [CrossRef]

89. Pasello, M.; Manara, M.C.; Scotlandi, K. CD99 at the crossroads of physiology and pathology. J. Cell Commun. Signal. 2018, 12, 55-68. [CrossRef]

90. Yao, Y.; Bellon, M.; Shelton, S.N.; Nicot, C. Tumor suppressors p53, p63TA $\alpha$, p63TAy, p73 $\alpha$, and p73 $\beta$ use distinct pathways to repress telomerase expression. J. Biol. Chem. 2012, 287, 20737-20747. [CrossRef]

91. Jung, M.S.; Yun, J.; Chae, H.D.; Kim, J.M.; Kim, S.C.; Choi, T.S.; Shin, D.Y. p53 and its homologues, p63 and p73, induce a replicative senescence through inactivation of NF-Y transcription factor. Oncogene 2001, 20, 5818-5825. [CrossRef]

92. Alimov, A.P.; Park-Sarge, O.K.; Sarge, K.D.; Malluche, H.H.; Koszewski, N.J. Transactivation of the parathyroid hormone promoter by specificity proteins and the nuclear factor Y complex. Endocrinology 2005, 146, 3409-3416. [CrossRef]

93. Jääskeläinen, T.; Huhtakangas, J.; Mäenpää, P. Negative regulation of human parathyroid hormone gene promoter by vitamin D3 through nuclear factor Y. Biochem. Biophys. Res. Commun. 2005, 328, 831-837. [CrossRef]

94. Josephs, E.B.; Stinchcombe, J.R.; Wright, S.I. What can genome-wide association studies tell us about the evolutionary forces maintaining genetic variation for quantitative traits? New Phytol. 2017, 214, 21-33. [CrossRef]

95. Li, B.; Zhang, N.; Wang, Y.G.; George, A.W.; Reverter, A.; Li, Y. Genomic prediction of breeding values using a subset of SNPs identified by three machine learning methods. Front. Genet. 2018, 9, 237. [CrossRef] [PubMed]

96. Mikšík, I.; Eckhardt, A.; Sedláková, P.; Mikulikova, K. Proteins of insoluble matrix of avian (Gallus gallus) eggshell. Connect. Tissue Res. 2007, 48, 1-8. [CrossRef] [PubMed]

97. Mikšík, I.; Sedláková, P.; Lacinová, K.; Pataridis, S.; Eckhardt, A. Determination of insoluble avian eggshell matrix proteins. Anal. Bioanal. Chem. 2010, 397, 205-214. [CrossRef] [PubMed]

98. He, L.; Sillanpää, M.J.; Silventoinen, K.; Kaprio, J.; Pitkäniemi, J. Estimating modifying effect of age on genetic and environmental variance components in twin models. Genetics 2016, 202, 1313-1328. [CrossRef]

99. Elks, C.E.; Den Hoed, M.; Zhao, J.H.; Sharp, S.J.; Wareham, N.J.; Loos, R.J.; Ong, K.K. Variability in the heritability of body mass index: A systematic review and meta-regression. Front. Endocrinol. 2012, 3, 29. [CrossRef]

100. Park, J.A.; Sohn, S.H. The Influence of Hen Aging on Eggshell Ultrastructure and Shell Mineral Components. Korean J. Food Sci. Anim. Resour. 2018, 38, 1080. [CrossRef]

101. Reimand, J.; Isserlin, R.; Voisin, V.; Kucera, M.; Tannus-Lopes, C.; Rostamianfar, A.; Wadi, L.; Meyer, M.; Wong, J.; Xu, C.; et al. Pathway enrichment analysis and visualization of omics data using g: Profiler, GSEA, Cytoscape and EnrichmentMap. Nat. Protoc. 2019, 14, 482-517. [CrossRef]

102. Neupane, M.; Geary, T.W.; Kiser, J.N.; Burns, G.W.; Hansen, P.J.; Spencer, T.E.; Neibergs, H.L. Loci and pathways associated with uterine capacity for pregnancy and fertility in beef cattle. PLOS ONE 2017, 12, e0188997. [CrossRef]

103. Woldesemayat, A.A.; Ntwasa, M. Pathways and Network Based Analysis of Candidate Genes to Reveal Cross-Talk and Specificity in the Sorghum (Sorghum bicolor (L.) Moench) Responses to Drought and It's Co-occurring Stresses. Front. Genet. 2018, 9, 557. [CrossRef]

104. Ramayo-Caldas, Y.; Renand, G.; Ballester, M.; Saintilan, R.; Rocha, D. Multi-breed and multi-trait co-association analysis of meat tenderness and other meat quality traits in three French beef cattle breeds. Genet. Sel. Evol. 2016, 48, 37. [CrossRef]

105. Kadarmideen, H.N.; von Rohr, P.; Janss, L.L. From genetical genomics to systems genetics: Potential applications in quantitative genomics and animal breeding. Mamm. Genome 2006, 17, 548-564. [CrossRef] [PubMed]

(C) 2020 by the authors. Licensee MDPI, Basel, Switzerland. This article is an open access article distributed under the terms and conditions of the Creative Commons Attribution (CC BY) license (http://creativecommons.org/licenses/by/4.0/). 